\title{
Competitividade da Agricultura Familiar no Rio Grande do Sul
}

\section{Competitiveness of Family Farming in Rio Grande do Sul}

\section{Competitivdad de la Agricultura Familiar en Rio Grande do Sul}

\author{
Eliane Pinheiro de Sousa, $\mathrm{Dr}^{\mathrm{a}}$ \\ Universidade Regional do Cariri, Centro de Estudos Sociais Aplicados \\ Rua Antônio Luiz, nº 1167, Pimenta, CEP: 63105-000 - Crato, CE, \\ Brasil, Telefone: (088) 31021212 \\ e-mail: pinheiroeliane@hotmail.com \\ Reisoli Bender Filho, Dr. \\ Universidade Federal de Santa Maria, Centro de Ciências Sociais e \\ Humanas, Departamento de Ciências Administrativas \\ Universidade Federal de Santa Maria, Camobi, CEP: 97105900 - Santa \\ Maria, RS - Brasil, Telefone: (55) 32208000, Ramal: 9259, e-mail: \\ reisolibender@yahoo.com.br
}

\author{
Daniel Arruda Coronel, Dr. \\ Universidade Federal de Santa Maria, Departamento de Ciências \\ Administrativas \\ Prédio 74C, Térreo, Sala 4112, Bairro Camobi, km 9, CEP: 97105-900 - \\ Santa Maria, RS - Brasil, Telefone: (55) 32209296 \\ e-mail: daniel.coronel@uol.com.br
}

Airton Lopes Amorim, Dr.

Universidade Federal de Viçosa, Departamento de Economia Rural Avenida Peter Henry Rolfs, s/n, Centro, 36570-000 - Vicosa, MG Brasil, Telefone: (31) 38992215

Fax: (31) 38992219, e-mail: aimorim2007@gmail.com

\section{RESUMO}

Este estudo objetiva identificar os determinantes da competitividade da agricultura familiar nos municípios gaúchos; mensurar um índice de desempenho competitivo da agricultura familiar (IDAF) em tais municípios; e verificar se há diferença significativa na competitividade da agricultura familiar entre as mesorregiões gaúchas. Para tal, utilizaram-se os métodos de estatística multivariada de análise fatorial e os testes paramétricos de Levene e $t$ de Student para dados não pareados. Os resultados indicaram que apenas dois municípios gaúchos apresentaram alto nível de desempenho competitivo da agricultura familiar, considerando os parâmetros estabelecidos. Verificou-se também que há diferenças significativas na competitividade da agricultura familiar entre as mesorregiões gaúchas.

Palavras-chave: Agricultura familiar. Desempenho competitivo. Rio Grande do Sul.

\section{ABSTRACT}

This study aims to identify the determinants of competitiveness of family farming in cities from the state of Rio Grande do Sul. The objective is also to measure an index of competitive performance of family farming (IDAF) in such cities and also to check for significant differences in competitiveness of family farming between mesoregions of Rio Grande do Sul. In order to accomplish that, it was used the multivariate statistical factor analysis and parametric tests of Levene and t of Student for unpaired data. The results indicated that only two cities in the state of Rio Grande do Sul showed a high level of competitive performance of family farming, considering the established parameters. There are significant differences in the competitiveness of family farming between the mesoregions of Rio Grande do Sul.

Keywords: Family farming; Competitive Performance; Rio Grande do Sul.

\footnotetext{
I Artigo recebido em 11.10.2014. Revisado pelos pares em 23.02.2015 (blind review). Ajustado e Aceito para publicação em 23.03.2015. Recomendado para publicação por José Ribamar Marques de Carvalho (Editor Científico). Publicado em 01.04.2015. Organização responsável CCJS/UFCG.
} 


\section{RESUMEN}

Este estudio objetiva identificar los determinantes de la competitividad de la agricultura familiar en los municipios gauchos; mensurar un índice de desempeño competitivo de la agricultura familiar (IDAF) en dichos municipios; $y$ verificar si hay diferencia significativa en la competitividad de la agricultura familiar entre las mesorregiones gauchas. Para ello, se utilizaron los métodos de estadística multivariada de análisis factorial y los testes paramétricos de Levene y $t$ de Student para datos no apareados. Los resultados indicaron que solamente dos municipios gauchos presentó alto nivel de desempeño competitivo de la agricultura familiar, si se consideran los parámetros establecidos. Se verificó también que hay diferencias significativas en la competitividad de la agricultura familiar entre las mesorregiones gauchas.

Palabras clave: Agricultura familiar. Desempeño competitivo. Rio Grande do Sul

\section{INTRODUÇÃO}

A agricultura familiar, além de colaborar com a redução do êxodo rural e servir como fonte de recursos para as famílias que dispõem de menores rendas, também contribui com a geração de riqueza, considerando não apenas a economia do setor agropecuário, mas a do próprio país (GUILHOTO et al., 2007).

Segundo dados do Censo Agropecuário de 2006, divulgados pelo Instituto Brasileiro de Geografia e Estatística (IBGE, 2014), a agricultura familiar é responsável por aproximadamente $70 \%$ dos alimentos consumidos pela população brasileira, por cerca de 40\% do Valor Bruto da Produção Agropecuária do país, sendo 4,3 milhões o número de estabelecimentos, os quais geram cerca de R $\$ 4$ bilhões ao ano.

Embora a produção familiar apresente estreita inter-relação com diversos segmentos da indústria e dos serviços, a expansão desse segmento da agricultura está, em grande medida, condicionada às políticas governamentais (CORONEL et al., 2013). Na concepção de Guilhoto et al. (2007), as políticas destinadas ao segmento familiar de crédito, de assistência técnica, de pesquisa e de comercialização, que buscam incrementar a produtividade do trabalho, são fundamentais para o crescimento e a sustentabilidade econômica desses agricultores. Essa grande relevância desse segmento é confirmada por França et al. (2009) por meio da apresentação de dados do Censo Agropecuário de 2006.

Quanto ao Rio Grande do Sul, conforme Brixius (2006), a agricultura familiar é responsável por $27 \%$ do Produto Interno Bruto (PIB) no Estado e produz $89 \%$ do leite, $74 \%$ do milho, $58 \%$ da soja, $74 \%$ das aves, $71 \%$ de suínos, $38 \%$ de bovinos de corte e 97\% do fumo. Com base no Censo Agropecuário (IBGE, 2014), 85,75\% dos estabelecimentos agropecuários estão nas mãos de produtores familiares e 76,80\% dos homens ocupados em atividades rurais nesse Estado são provenientes da agricultura familiar.

Nesse contexto, em face da relevância dessa temática no Estado do Rio Grande do Sul, este estudo objetiva identificar os fatores determinantes da competitividade da agricultura familiar nos municípios gaúchos; mensurar um índice de desempenho 
competitivo para a agricultura familiar; e verificar se há diferença significativa na competitividade da agricultura familiar entre as mesorregiões gaúchas.

\section{FUNDAMENTAÇÃO TEÓRICA}

Apesar de os estudos sobre competitividade serem frequentes, não há um consenso quanto à definição do conceito e das metodologias mais apropriadas de avaliação. A maioria dos estudos trata a competitividade como um fenômeno diretamente associado às características de desempenho ou de eficiência técnica e alocativa e considera a competitividade como a agregação desses resultados. Sob a ótica do desempenho, a competitividade é expressa pela participação no mercado obtida por uma firma em um mercado em um dado momento do tempo. Já sob o ponto de vista da eficiência, a competitividade se traduz de alguma forma por meio da relação insumo-produto praticada pela firma (FERRAZ et al., 1995).

Para mensurar o desempenho competitivo das unidades produtivas, a literatura econômica de organização industrial tem empregado o referencial teórico dos modelos de estrutura-conduta-desempenho (ECD), de Porter concernente às cinco forças competitivas e da competitividade sistêmica (SANTANA, 2003, 2007; GAMA et al., 2007; SOUSA et al., 2010; BARBOSA; SOUSA, 2012).

De acordo com Santana (2007) e Gama et al. (2007), a competitividade empresarial consiste no esforço realizado pelas empresas para se manterem no mercado, permanecendo e, ou ampliando sua parcela de mercado. Esse conceito de competitividade se baseia nos postulados do modelo estrutura-conduta-desempenho (ECD), em que a estrutura das indústrias determina a conduta, que, por sua vez, influencia o desempenho das empresas. Essas dimensões podem se associar com este presente estudo, visto que variáveis como, por exemplo, despesas com insumos animais e vegetais fazem parte da estrutura; assistência técnica e nível de escolaridade constituem a dimensão conduta e valor da produção e estabelecimentos que são muito integrados representam a dimensão desempenho.

$\mathrm{Na}$ concepção desses autores, esse conceito de competitividade não é considerado operacional. Desta forma, com o intuito de remover essa dificuldade, Porter (1993) ressaltou que as variáveis que determinam as dimensões do modelo ECD não são estáticas, porém atuam de forma dinâmica. Assim, esse modelo considera cinco dimensões: ameaça de novos concorrentes, pressão de produtos substitutos, rivalidade entre os concorrentes e poder de barganha dos fornecedores e dos compradores. Essas forças podem ser observadas neste trabalho como, por exemplo, as despesas com insumos, o número de máquinas e implementos agrícolas se relacionam à ameaça de novos concorrentes; o uso de adubos e corretivos e a conservação do solo refletem a diversificação dos produtos; o valor da produção e se os estabelecimentos são muito integrados fazem parte da força rivalidade entre os 
concorrentes. Essas forças podem ameaçar a sustentabilidade do desempenho e, a partir de sua identificação, podem-se obter oportunidades.

Para Esser et al. (1996), a competitividade empresarial é o resultado da interação sistêmica de fatores como a infraestrutura, a política, a cultura, a inovação tecnológica e de gestão e o ambiente institucional que atuam em toda cadeia produtiva. Tais fatores podem ser agrupados nos níveis micro, macro, meso e meta. Associando esses níveis com este trabalho, percebe-se que o nível de escolaridade faz parte do mesonível, enquanto as demais variáveis compreendem o micronível.

Portanto, neste estudo, emprega-se um método analítico de estatística multivariada, conforme descrito na próxima seção, que considera a interação desses diversos fatores que influenciam a competitividade.

\section{MÉTODOS DE PESQUISA}

As áreas de estudo deste trabalho contemplaram 489 dos 496 municípios gaúchos, sendo removidos da análise os municípios de Arambaré, Balneário Pinhal, Capão da Canoa, Esteio, Minas do Leão, São Vendelino e Xangri-lá. Essa seleção foi baseada na disponibilidade de dados para todas as variáveis contidas neste estudo. Os dados foram obtidos do Censo Agropecuário 2006 (IBGE, 2014).

Para identificar os fatores determinantes da competitividade da agricultura familiar nos municípios gaúchos e mensurar um índice de desempenho competitivo para a agricultura familiar (IDAF), utilizou-se a técnica estatística multivariada de Análise Fatorial. De acordo com Fávero et al. (2009), esse método busca identificar um número relativamente pequeno de fatores comuns que podem ser empregados para representar relações entre um grande número de variáveis inter-relacionadas, cuja operacionalização pode ser constituída pelas seguintes etapas: análise da matriz de correlações e adequabilidade do método; extração dos fatores iniciais e determinação do número de fatores; rotação dos fatores; e interpretação dos fatores.

Inicialmente, buscou-se avaliar a matriz de correlações e verificar se há valores significativos para justificar o emprego dessa técnica. Um indício de que a Análise Fatorial seja apropriada manifesta-se quando as correlações entre todas as variáveis forem reduzidas, enquanto as variáveis que fazem parte do mesmo fator apresentam alta correlação. O segundo passo consistiu no emprego do método de extração dos fatores, em que se utilizou a Análise dos Componentes Principais, visto que considera a variância total dos dados. Ademais, deve-se escolher o número de fatores, usando o critério da raiz latente, em que se escolhe o número de fatores com base no número de valores próprios superior à unidade. Em seguida, realizou-se a rotação dos fatores para facilitar a interpretação. A última etapa refere-se à interpretação e nomeação dos fatores (FÁVERO et al., 2009).

Os escores fatoriais para cada município gaúcho foram utilizados na formação do índice de desempenho competitivo da agricultura familiar (IDAF) nos municípios 
gaúchos. Para se determinar esse índice, este estudo tomou como base os estudos desenvolvidos por Santana (2007), para o índice de desempenho competitivo das empresas de polpa de frutas paraenses; por Sousa e Campos (2010), para o índice de desempenho competitivo dos fruticultores cearenses localizados em diferentes áreas irrigadas do estado do Ceará; e por Barbosa e Sousa (2012), para o índice de desempenho competitivo dos apicultores fixos e migratórios da microrregião cearense do Cariri.

Com base nesses estudos, esse índice pode ser representado pela combinação linear dos escores fatoriais, obtidos pela Análise Fatorial, como a proporção da variância explicada pelos fatores individuais em relação à variância comum. Matematicamente, o IDAF pode ser expresso por: IDAF $=\sum_{j=1}^{k}\left(\frac{\lambda_{j}}{\sum_{j=1}^{k} \lambda_{j}} F P_{j i}\right)$ (1), em que: IDAF é o índice de desempenho competitivo da agricultura familiar nos municípios gaúchos; $\lambda_{j}$, percentual da variância explicada pelo fator $\mathrm{j}$; $\mathrm{k}$, número de fatores escolhidos; $\boldsymbol{F} \boldsymbol{P}_{j i}$, escore fatorial, padronizado pelo município i, do fator j, que pode ser representado por: $\quad F P_{j i}=\frac{F_{j}-F_{\min }}{F_{\max }-F_{\min }}$ (2), em que $F_{\text {min }}$ é o escore fatorial mínimo do fator j; e $F_{\text {max }}$, escore fatorial máximo do fator $\mathrm{j}$.

O cálculo desse índice fornece um número que varia de zero a um. Para facilitar a interpretação dos resultados, considera-se que os municípios gaúchos que tiveram valores do IDAF iguais ou superiores a 0,70 tenham registrado elevado desempenho competitivo da agricultura familiar; os que apresentaram valores compreendidos de 0,35 a 0,69, desempenho competitivo intermediário; e os com valores do IDAF menores do que 0,35, baixo desempenho competitivo. Esses intervalos de valores do IDAF foram escolhidos com base na especificação estabelecida nesses estudos referenciados.

As variáveis que fizeram parte da mensuração do IDAF são: V1 (valor da produção com lavouras permanentes e temporárias nos estabelecimentos agropecuários com agricultura familiar em relação ao número total desses estabelecimentos); V2 (despesas com insumos animais e vegetais dos estabelecimentos agropecuários com agricultura familiar em relação ao número total desses estabelecimentos); V3 (número de estabelecimentos agropecuários com agricultura familiar que sejam muito integrados ${ }^{\mathrm{II}}$ em relação ao número total desses

\footnotetext{
II De acordo com o Censo Agropecuário 2006 (IBGE, 2014), um estabelecimento agropecuário pode ser considerado como muito integrado se o grau de integração ao mercado (FAO/INCRA), expresso pela relação entre o total da receita com atividade agropecuária e o valor total da produção agropecuária, for igual ou maior do que 0,9 .
} 
estabelecimentos); V4 (número de máquinas e implementos agrícolas existentes nos estabelecimentos agropecuários com agricultura familiar em relação ao número total desses estabelecimentos); V5 (número de estabelecimentos agropecuários com agricultura familiar que recebe assistência técnica em relação ao número total desses estabelecimentos); V6 (número de estabelecimentos agropecuários com agricultura familiar que utiliza adubos e corretivos em relação ao número total desses estabelecimentos); V7 (número de estabelecimentos agropecuários com agricultura familiar que faz conservação de solo em relação ao número total desses estabelecimentos) e V8 (número de estabelecimentos agropecuários com agricultura familiar em que a pessoa que dirige o estabelecimento possui pelo menos Ensino Fundamental).

Além desse método analítico, empregaram-se os testes paramétricos de Levene e $\mathrm{t}$ de Student para dados não pareados com o intuito de verificar se há diferença significativa na competitividade da agricultura familiar entre as mesorregiões gaúchas. Esses métodos foram operacionalizados pelo software SPSS 21. De acordo com Maia et al. (2013), o teste de Levene busca testar a homogeneidade de variâncias, cuja estatística utilizada no teste é obtida a partir de uma análise de variância com base em um único fator, pois o nível de observação é a população, logo se dá a substituição de cada item i pelo desvio absoluto da variável em relação à média do seu respectivo grupo.

Neste estudo, foram admitidas as pressuposições consideradas por Maia et al. (2013) de que $\mathrm{K}=2$ amostras aleatórias e independentes, sendo que cada amostra $i$ corresponde a um conjunto de $n_{i}$ variáveis aleatórias, as quais foram comparadas para testar as hipóteses de igualdade ou não entre as variâncias. Portanto, replicando para este estudo, têm-se as seguintes hipóteses: hipótese nula $\left(\mathrm{H}_{0}\right): \sigma_{1}^{2}=\sigma_{2}^{2}$, se não existirem diferenças significativas entre as variâncias do IDAF entre as mesorregiões rio-grandenses e hipótese alternativa $\left(\mathrm{H}_{1}\right): \sigma_{1}^{2} \neq \sigma_{2}^{2}$, se existirem diferenças significativas entre as variâncias do IDAF.

Quanto ao teste $\mathrm{t}$ para dados não pareados, conforme Triola (1999), este se refere a um teste paramétrico que permite comparar uma mesma variável, de duas amostras diferentes, em um dado instante no tempo. Esse teste possui as seguintes suposições: as duas amostras precisam ser independentes, devem ser obtidas de forma aleatória e serem normalmente distribuídas. As hipóteses do teste consideradas neste estudo foram hipótese nula $\left(\mathrm{H}_{0}\right): \mu_{1}=\mu_{2}$, se não existirem diferenças significativas entre as médias do IDAF entre as mesorregiões riograndense e a hipótese alternativa $\left(\mathrm{H}_{1}\right): \mu_{1} \neq \mu_{2}$, se existirem diferenças significativas entre as médias do IDAF.

\section{ANÁliSE E DISCUSSÃO DOS RESULTADOS}


Essa seção está estruturada em quatro partes, sendo que a primeira apresenta as estatísticas descritivas das variáveis que fizeram parte deste estudo; a segunda se dedica aos resultados referentes à análise fatorial; na terceira, realiza-se a hierarquização dos municípios gaúchos conforme os escores fatoriais e o índice de desempenho da agricultura familiar; e por fim, na última parte desta seção, são mostrados os resultados do desempenho da agricultura familiar por mesorregião Rio-Grandense.

\subsection{Caracterização da agricultura familiar nos municípios gaúchos}

Para caracterizar os municípios gaúchos quanto à agricultura familiar, a Tabela 1 apresenta as principais estatísticas descritivas das variáveis consideradas na análise fatorial. Conforme se verifica, os estabelecimentos agropecuários com agricultura familiar detêm, em média, um valor da produção com lavouras permanentes e temporárias de $\mathrm{R} \$ 13.289,03$, sendo que o município de Chuí, sediado na mesorregião Sudeste Rio Grandense, foi o que obteve o menor valor $(R \$ 1,40)$ por estabelecimento agropecuário. Esse baixo valor pode ser atribuído à ausência de produção com lavouras permanentes e seu valor com lavouras temporárias ter sido somente $\mathrm{R} \$ 28,00$ para os 20 estabelecimentos agropecuários com agricultura familiar neste município.

Em contrapartida, o município de Mato Queimado, que faz parte da mesorregião Noroeste Rio Grandense, se destacou com o maior valor da produção municipal do Rio Grande do Sul correspondendo a $\mathrm{R} \$ 126.854,37$ por estabelecimento agropecuário com agricultura familiar. No tocante a esse município, vale ressaltar que, em termos absolutos, não foi o que apresentou maior valor produzido com cultivos permanentes e temporários, porém ao se considerar em termos relativos ao número de estabelecimentos agropecuários com agricultura familiar, o referido município liderou esse ranking. A elevada dispersão entre esses valores justificam o fato de essa variável ter se destacado com o maior coeficiente de variação, dentre as variáveis consideradas neste estudo.

Em relação às despesas com insumos animais e vegetais por estabelecimento agropecuário com agricultura familiar, os dados apontam que o município de Santa Bárbara do Sul, localizado na mesorregião Noroeste Rio Grandense, foi o que registrou a menor despesa ( $\mathrm{R} \$ 168,40)$ com tais insumos por estabelecimento agropecuário na agricultura familiar, ao passo que Boa Vista das Missões, sediada nessa mesma mesorregião, teve o maior dispêndio ( $\mathrm{R} \$ 20.789,02$ ) com esse item. Esses dados demonstram a existência de alta heterogeneidade dentro da própria mesorregião, que deteve os valores mínimos e máximos dessa variável. Em termos médios, os municípios gaúchos dispendem $\mathrm{R} \$ 4.022,43$ com tais insumos.

Os dados revelam que o município que deteve a menor participação de estabelecimentos agropecuários que sejam muito integrados na agricultura familiar 
ocorreu em Palmitinho, pertencente à mesorregião Noroeste Rio Grandense, uma vez que, dos 1.039 estabelecimentos agropecuários com agricultura familiar, somente 19 desses são muito integrados. Por outro lado, no município de Canoas, localizado na mesorregião Metropolitana de Porto Alegre, dos 31 estabelecimentos agropecuários com agricultura familiar, 29 deles foram classificados como muito integrados, obtendo, assim, a maior participação relativa de estabelecimentos agropecuários que sejam muito integrados na agricultura familiar no estado do Rio Grande do Sul.

No que concerne ao número de máquinas e implementos agrícolas, observa-se que os estabelecimentos agropecuários gaúchos com agricultura familiar possuem, em média, duas máquinas e implementos agrícolas, sendo que a menor participação ocorreu no município de Cambará do Sul, sediado no Nordeste gaúcho, que possui 43 máquinas e implementos agrícolas para atender a 270 estabelecimentos agropecuários na agricultura familiar, enquanto o município de Nova Pádua, também no Nordeste gaúcho, dispõe de 2.013 máquinas e implementos agrícolas para 349 estabelecimentos agropecuários na agricultura familiar.

Tabela 1 - Estatísticas descritivas das variáveis que fizeram parte deste estudo

\begin{tabular}{lcccc}
\hline Variáveis & Mínimo & Média & Máximo & Coeficiente de variação $(\%)$ \\
\hline V1 & 1,40 & $13.289,03$ & $126.854,37$ & 88,90 \\
V2 & 168,40 & $4.022,43$ & $20.789,02$ & 72,24 \\
V3 & 0,02 & 0,25 & 0,94 & 58,33 \\
V4 & 0,16 & 1,98 & 5,77 & 50,59 \\
V5 & 0,02 & 0,51 & 0,98 & 42,03 \\
V6 & 0,16 & 0,80 & 0,99 & 21,09 \\
V7 & 0,07 & 0,74 & 0,99 & 27,52 \\
V8 & 0,04 & 0,17 & 0,80 & 44,95 \\
\hline
\end{tabular}

Fonte: Elaborado pelos autores com base nos dados da pesquisa.

No tocante à participação relativa de estabelecimentos agropecuários com agricultura familiar que utilizam assistência técnica, percebe-se que, em média, apenas 0,51 desses estabelecimentos recebem esse acompanhamento técnico, sendo que a pior situação foi encontrada no município de Caraá, pertencente à mesorregião Metropolitana de Porto Alegre, cuja proporção foi somente de 0,02. Em outros termos, esse resultado mostra que, dos 1.075 estabelecimentos agropecuários com agricultura familiar, somente 24 desses recebem orientação técnica. Por outro lado, a maior participação foi detectada no município de Engenho Velho, que faz parte do Noroeste gaúcho, sendo que dos 212 estabelecimentos agropecuários com agricultura familiar, 207 desses recebem orientação técnica.

Verifica-se também que, em média, 0,8 estabelecimentos agropecuários com agricultura familiar no Rio Grande do Sul fazem uso de adubos e corretivos, sendo que Lavras do Sul, pertencente ao Sudoeste gaúcho, deteve a menor participação relativa $(0,16)$, ou seja, dos 645 estabelecimentos agropecuários com agricultura familiar, apenas 100 deles adota essa prática. Por outro lado, no município de Arroio 
do Padre, sediado no Sudeste gaúcho, a participação relativa foi de 0,99 , indicando que 498 estabelecimentos agropecuários com agricultura familiar do total de 501 empregam essa variável, isto é, apenas três deles não utilizam adubos e corretivos em seus cultivos familiares. Dentre as variáveis analisadas neste estudo, essa foi a que apresentou a menor variabilidade entre os municípios gaúchos.

Quanto à conservação do solo, os dados indicam que a participação relativa de estabelecimentos agropecuários com agricultura familiar que realiza essa prática, em termos médios, é 0,74 , sendo que o município com menor participação foi Relvado, no Centro Oriental Rio Grandense, em que somente 26 dos 385 estabelecimentos adotam essa prática, enquanto o município de Engenho Velho foi o que teve a maior participação de estabelecimentos agropecuários que fazem conservação de solo $(0,99)$, sinalizando que dos 212 estabelecimentos agropecuários com agricultura familiar neste município, somente um único não faz conservação do solo.

Ademais, em face da relevância desempenhada pela escolaridade na competitividade agrícola, essa variável também fez parte deste estudo. Entretanto, apesar de sua enorme contribuição, constata-se por meio da análise descritiva que, em média, apenas 17,14\% dos estabelecimentos agropecuários com agricultura familiar são dirigidos por pessoas que possuam pelo menos ensino fundamental. Em relação a essa variável, o município de Tramandaí, pertencente à mesorregião Metropolitana de Porto Alegre, registrou a menor participação relativa, tendo em vista que somente um único estabelecimento agropecuário com agricultura familiar se encontra nessas condições. Em contrapartida, no município de Chuí, dos 20 estabelecimentos agropecuários com agricultura familiar, 16 deles são dirigidos por pessoas com pelo menos ensino fundamental.

\subsection{Análise fatorial}

Para se aplicar a análise fatorial, inicialmente deve-se verificar se esse método é apropriado aos dados considerados. O teste estatístico de esfericidade de Bartlett mostrou-se significativo a $1 \%$ de probabilidade, com valor de $1.514,83$. Essa adequabilidade dos dados também é confirmada por meio do teste de Kaiser-MeyerOlkim (KMO), que apresentou valor de 0,81. De acordo com Fávero et al. (2009), quando os valores do KMO pertencem ao intervalo entre 0,80 e 0,90, como é o caso deste estudo, a utilização desta técnica apresenta boa adequação da amostra.

Portanto, ao se constatar que esse método analítico foi adequado à base de dados estudada, utilizou-se a análise fatorial pelo método dos componentes principais. Entretanto, vale destacar que, em sua versão original, uma variável pode se relacionar com mais de um fator, dificultando a interpretação. Assim, com o intuito de remover esse tipo de problema, adotou-se a rotação ortogonal pelo método Varimax, cujas raízes características da matriz de correlações com valores superiores a um e suas respectivas porcentagens da variância total explicada se encontram na 
Tabela 2. Esses fatores de competitividade da agricultura familiar gaúcha são capazes de explicar 74,25\% da variância total dos dados.

Tabela 2 - Raízes características da matriz de correlações simples $(489$ × 8) para a agricultura familiar nos municípios gaúchos, 2006.

\begin{tabular}{cccc}
\hline Fatores & Raiz Característica & Variância explicada pelo fator (\%) & Variância acumulada (\%) \\
\hline 1 & 2,82 & 35,26 & 35,26 \\
2 & 1,99 & 24,93 & 60,19 \\
3 & 1,13 & 14,06 & 74,25 \\
\hline
\end{tabular}

Fonte: Elaborado pelos autores com base nos dados da pesquisa.

A Tabela 3 mostra as cargas fatoriais rotacionadas e as comunalidades para os fatores considerados. Neste estudo, as cargas fatoriais com valores absolutos a partir de 0,7 foram destacadas em negrito como indicativo das variáveis mais fortemente associadas a um dado fator. Os valores das comunalidades sinalizam que todas as variáveis apresentam sua variabilidade captada e representada pelos três fatores.

Conforme se observa, o fator F1 possui correlação positiva e expressiva com as variáveis V4 (número de máquinas e implementos agrícolas existentes nos estabelecimentos agropecuários com agricultura familiar em relação ao número total desses estabelecimentos), V5 (número de estabelecimentos agropecuários com agricultura familiar que recebe assistência técnica em relação ao número total desses estabelecimentos), V6 (número de estabelecimentos agropecuários com agricultura familiar que utiliza adubos e corretivos em relação ao número total desses estabelecimentos) e V7 (número de estabelecimentos agropecuários com agricultura familiar que faz conservação de solo em relação ao número total desses estabelecimentos).

Esse fator contempla a dimensão concernente ao uso intensivo de tecnologia no fator terra, indicando que essas variáveis desempenham papel importante para a competitividade da agricultura familiar, podendo se associar com os modelos ECD, das cinco forças competitivas de Porter e da abordagem sistêmica, descrito no referencial teórico. Esse fator pode ser nomeado pela dimensão relativa à gestão competitiva sustentável. Desta forma, para que essas unidades familiares conquistem maior produtividade do fator terra, fortalecendo a competitividade de forma sustentável, torna-se necessário seguir as orientações recomendadas pelos técnicos quanto às práticas sustentáveis de uso da terra, adotando tecnologias adequadas.

Tabela 3 - Cargas fatoriais após rotação ortogonal e comunalidades para a agricultura familiar nos municípios gaúchos, 2006.

\begin{tabular}{|c|c|c|c|c|}
\hline \multirow[t]{2}{*}{ Variáveis } & \multicolumn{3}{|c|}{ Cargas fatoriais } & \multirow[t]{2}{*}{ Comunalidades } \\
\hline & F1 & F2 & F3 & \\
\hline V1 & 0,23 & 0,83 & $-0,21$ & 0,77 \\
\hline V2 & 0,50 & 0,70 & 0,11 & 0,76 \\
\hline V3 & $-0,03$ & 0,78 & 0,32 & 0,71 \\
\hline V4 & 0,82 & 0,05 & $-0,05$ & 0,67 \\
\hline \multicolumn{5}{|c|}{$\begin{array}{l}\text { REUNIR - Revista de Administração, Contabilidade e Sustentabilidade } \\
\text { ISSN: 2237-3667 - Vol.5, no1, pp. 106-123, } 2015 . \\
115\end{array}$} \\
\hline
\end{tabular}




\begin{tabular}{lcccc} 
V5 & $\mathbf{0 , 7 1}$ & 0,40 & 0,09 & 0,68 \\
V6 & $\mathbf{0 , 8 6}$ & 0,18 & $-0,16$ & 0,79 \\
V7 & $\mathbf{0 , 7 7}$ & 0,09 & $-0,20$ & 0,63 \\
V8 & $-0,15$ & 0,09 & $\mathbf{0 , 9 5}$ & 0,93 \\
\hline
\end{tabular}

Fonte: Elaborado pelos autores com base nos dados da pesquisa.

Quanto ao fator F2, verifica-se uma associação forte e positiva com as variáveis V1 (valor da produção com lavouras permanentes e temporárias nos estabelecimentos agropecuários com agricultura familiar em relação ao número total desses estabelecimentos), V2 (despesas com insumos animais e vegetais dos estabelecimentos agropecuários com agricultura familiar em relação ao número total desses estabelecimentos) e V3 (número de estabelecimentos agropecuários com agricultura familiar que sejam muito integrados em relação ao número total desses estabelecimentos). Essas variáveis em conjunto com sinais positivos e valores elevados conduzem a um maior desempenho competitivo da agricultura familiar, estando consistente com a teoria econômica, uma vez que, Coeteris paribus, quanto maior o valor da produção, maior será a integração com o mercado e maiores serão os rendimentos obtidos, o que está associado a maiores despesas com insumos. Esse fator capta as variáveis que representam a dimensão concernente à produção, às despesas com insumos e à integração, sendo que a variável V1 é a mais relevante na composição deste fator, já que apresenta o coeficiente com maior magnitude. Assim, este fator F2 pode ser nomeado dimensão gestão competitiva tradicional, tendo em vista que tais variáveis se enquadram nas dimensões estrutura e desempenho do modelo ECD, na força rivalidade do modelo de Porter e no micronível do modelo de competividade sistêmica.

Por sua vez, o fator F3, que explica $14,06 \%$ da variância total dos dados, é constituído pela variável V8 (número de estabelecimentos agropecuários com agricultura familiar em que a pessoa que dirige o estabelecimento possui pelo menos ensino fundamental). Esse fator reflete a dimensão intelectual dos produtores familiares, que se associa ao mesonível do modelo de competitividade sistêmica. Isso significa que, se dado produtor apresentar o escore desse fator positivo e elevado indica que o mesmo possui elevado nível intelectual, o que contribui positivamente para a competitividade da agricultura familiar.

\subsection{Hierarquização dos municípios gaúchos quanto aos escores fatoriais e o desempenho competitivo da agricultura familiar}

Tendo em vista que um determinado município gaúcho pode apresentar características distintas quanto aos fatores de competitividade da agricultura familiar, é importante identificar os municípios, com suas respectivas mesorregiões que se destacam com os maiores e os menores escores para cada fator considerado. Desta forma, as Tabelas 4, 5 e 6 mostram os municípios gaúchos, respectivamente, 
considerando a gestão competitiva sustentável (F1), gestão competitiva tradicional (F2) e dimensão intelectual dos produtores familiares (F3).

A partir dos dados contidos na Tabela 4, constata-se que dentre os dez municípios que se destacaram com melhores escores fatoriais concernentes à gestão competitiva sustentável, sete desses se localizam na mesorregião Noroeste RioGrandense. Dentre tais municípios, encontra-se Nova Pádua, que apresentou a maior participação relativa de máquinas e implementos agrícolas por estabelecimento agropecuário com agricultura familiar e Engenho Velho, que obteve as maiores participações relativas de assistência técnica e conservação do solo.

Tabela 4 - Os dez maiores e os dez menores escores fatoriais originais referentes à gestão competitiva sustentável (F1) da agricultura familiar nos municípios gaúchos.

\begin{tabular}{cccccc}
\hline Municípios & Mesorregiões & $\begin{array}{c}\text { Maiores } \\
\text { escores } \\
\text { F1 }\end{array}$ & Municípios & $\begin{array}{c}\text { Mesorregiões } \\
\text { Menores } \\
\text { escores } \\
\text { F2 }\end{array}$ \\
\hline Chuvisca & Metropolitana & 2,23 & Dom Pedrito & Sudoeste & $-2,12$ \\
Selbach & Noroeste & 2,04 & Uruguaiana & Sudoeste & $-2,14$ \\
Nova Pádua & Nordeste & 1,83 & Morrinhos do Sul & Metropolitana & $-2,33$ \\
Nova Boa Vista & Noroeste & 1,80 & Bagé & Sudoeste & $-2,35$ \\
Aratiba & Noroeste & 1,76 & Itaqui & Sudoeste & $-2,38$ \\
Engenho Velho & Noroeste & 1,74 & Santa Vitória do Palmar & Sudeste & $-2,50$ \\
Novo Xingu & Noroeste & 1,72 & Rosário do Sul & Sudoeste & $-2,61$ \\
Tapera & Noroeste & 1,70 & Pinheiro Machado & Sudeste & $-2,62$ \\
Lagoa dos Três Cantos & Noroeste & 1,66 & Quaraí & Sudoeste & $-2,81$ \\
Canudos do Vale & Centro Oriental & 1,62 & Lavras do Sul & Sudoeste & $-2,89$ \\
\hline
\end{tabular}

Fonte: Elaborado pelos autores com base nos dados da pesquisa.

Em contrapartida, os dez menores escores desse fator foram concentrados na mesorregião Sudoeste Rio-Grandense, sendo que Lavras do Sul registrou o menor valor desse fator, podendo ser atribuído ao fato de ter apresentado o menor valor referente à proporção de estabelecimentos agropecuários com agricultura familiar que utilizam adubos e corretivos em seus cultivos.

Com base nos dados apresentados na Tabela 5, nota-se que a mesorregião Noroeste Rio-Grandense também se destaca quanto ao fator que capta a gestão competitiva tradicional da agricultura familiar dentre os dez municípios que lideraram o ranking dos maiores escores desse fator, sendo que o município de Mato Queimado conquistou o maior escore fatorial, podendo estar associado ao fato deste município ter obtido o maior valor da produção com lavouras permanentes e temporárias. Por outro lado, a mesorregião que predominou com os menores escores fatoriais foi o Centro Oriental, uma vez que dos dez municípios com piores escores, oito deles se encontram nessa mesorregião. 
Tabela 5 - Os dez maiores e os dez menores escores fatoriais originais referentes à gestão competitiva tradicional (F2) da agricultura familiar nos municípios gaúchos.

\begin{tabular}{cccccc}
\hline Municípios & Mesorregiões & $\begin{array}{c}\text { Maiores } \\
\text { escores }\end{array}$ & Municípios & Mesorregiões & $\begin{array}{c}\text { Menores } \\
\text { escores } \\
\text { F2 }\end{array}$ \\
\hline Mato Queimado & Noroeste & 5,03 & Coqueiro Baixo & Centro Oriental & $-1,42$ \\
Herveiras & Centro Oriental & 4,15 & Lajeado & Centro Oriental & $-1,45$ \\
Carazinho & Noroeste & 3,59 & Capitão & Centro Oriental & $-1,53$ \\
Palmares do Sul & Metropolitana & 3,23 & Canudos do Vale & Centro Oriental & $-1,53$ \\
Cruz Alta & Noroeste & 3,22 & Colinas & Centro Oriental & $-1,54$ \\
Inhacorá & Noroeste & 3,18 & Travesseiro & Centro Oriental & $-1,55$ \\
Colorado & Noroeste & 3,08 & Palmitinho & Noroeste & $-1,56$ \\
Bento Gonçalves & Nordeste & 2,97 & Sapucaia do Sul & Metropolitana & $-1,65$ \\
Santa Bárbara do Sul & Noroeste & 2,89 & Forquetinha & Centro Oriental & $-1,70$ \\
Flores da Cunha & Nordeste & 2,84 & Imigrante & Centro Oriental & $-1,79$ \\
\hline
\end{tabular}

Fonte: Elaborado pelos autores com base nos dados da pesquisa.

Quanto à dimensão intelectual, os dados da Tabela 6 apontam que, dentre os dez municípios com melhores escores fatoriais, sete deles fazem parte da mesorregião Metropolitana de Porto Alegre, porém o município com maior escore para esse fator foi Chuí, sediado no Sudeste Rio-Grandense. Conforme descrito anteriormente, esse município foi o que deteve a maior participação relativa de estabelecimentos agropecuários com agricultura familiar contendo dirigentes com pelo menos o ensino médio. Em contrapartida, dos dez municípios com piores escores relativos à dimensão intelectual, seis deles se encontram no Noroeste RioGrandense.

Tabela 6 - Os dez maiores e os dez menores escores fatoriais originais referentes à dimensão intelectual (F3) dos produtores familiares nos municípios gaúchos.

\begin{tabular}{cccccc}
\hline Municípios & Mesorregiões & $\begin{array}{c}\text { Maiores } \\
\text { escores F3 }\end{array}$ & Municípios & Mesorregiões & $\begin{array}{c}\text { Menores } \\
\text { escores F3 }\end{array}$ \\
\hline Chuí & Sudeste & 7,74 & Caraá & Metropolitana & $-1,38$ \\
Porto Alegre & Metropolitana & 4,24 & Tramandaí & Metropolitana & $-1,40$ \\
Canoas & Metropolitana & 4,20 & Cristal do Sul & Noroeste & $-1,40$ \\
Barra do Quaraí & Sudoeste & 4,13 & Sagrada Família & Noroeste & $-1,44$ \\
Estância Velha & Metropolitana & 3,58 & Morrinhos do Sul & Metropolitana & $-1,64$ \\
Sapucaia do Sul & Metropolitana & 3,51 & Alpestre & Noroeste & $-1,78$ \\
Cidreira & Metropolitana & 3,46 & Inhacorá & Noroeste & $-1,97$ \\
Carazinho & Noroeste & 2,79 & Ametista do Sul & Noroeste & $-2,21$ \\
Glorinha & Metropolitana & 2,69 & Herveiras & Centro Oriental & $-3,08$ \\
Capela de Santana & Metropolitana & 2,69 & Mato Queimado & Noroeste & $-3,49$ \\
\hline
\end{tabular}

Fonte: Elaborado pelos autores com base nos dados da pesquisa. 
Ao se considerar simultaneamente os três fatores na determinação do IDAF, percebe-se que os municípios pertencentes à mesorregião do Noroeste RioGrandense se destacaram com os maiores índices de desempenho da agricultura familiar, ao passo que os piores índices não tiveram concentração em nenhuma mesorregião específica, visto que, das sete mesorregiões gaúchas, cinco delas tiveram municípios que fizeram parte do ranking dos dez piores IDAF (Tabela 7).

Tabela 7 - Os dez maiores e os dez menores valores dos Índices de Desempenho da Agricultura Familiar (IDAF) nos municípios gaúchos.

\begin{tabular}{cccccc}
\hline Municípios & Mesorregiões & $\begin{array}{c}\text { Maiores } \\
\text { IDAF }\end{array}$ & Municípios & Mesorregiões & $\begin{array}{c}\text { Menores } \\
\text { IDAF }\end{array}$ \\
& & & Ametista do Sul & Noroeste & 0,21 \\
Carazinho & Noroeste & 0,71 & Noroeste & 0,21 \\
Nova Pádua & Nordeste & 0,70 & Santo Antônio das Missões & Sudoeste & 0,21 \\
Colorado & Noroeste & 0,68 & Itaqui & Metropolitana & 0,21 \\
Lagoa dos Três Cantos & Noroeste & 0,68 & Santo Antônio da Patrulha & Centro Ocidental & 0,19 \\
Selbach & Noroeste & 0,67 & Unistalda & Centro Ocidental & 0,18 \\
Tapera & Noroeste & 0,66 & Itacurubi & Sudoeste & 0,17 \\
Pejuçara & Noroeste & 0,65 & Rosário do Sul & Sudoeste & 0,17 \\
Canoas & Metropolitana & 0,63 & Quaraí & Sudeste & 0,16 \\
Ipiranga do Sul & Noroeste & 0,63 & Pinheiro Machado & Sudoeste & 0,16 \\
Erebango & Noroeste & 0,62 & Lavras do Sul & & \\
\hline
\end{tabular}

Fonte: Elaborado pelos autores com base nos dados da pesquisa.

\subsection{Caracterização do desempenho competitivo da agricultura familiar nas mesorregiões gaúchas}

De acordo com a Tabela 8, verifica-se, que, seguindo a classificação estabelecida na metodologia, parcela majoritária $(70,55 \%)$ dos municípios gaúchos apresenta um índice de competitividade intermediário da agricultura familiar, sendo que as mesorregiões do Centro Oriental, do Nordeste e do Noroeste apresentaram participações relativas com essa classificação superiores à média estadual. Somente dois municípios (Carazinho e Nova Pádua) pertencentes, respectivamente, às mesorregiões do Noroeste e Nordeste Rio-Grandense apresentou índice de desempenho competitivo da agricultura familiar de pelo menos 0,70, sendo, portanto, classificado como alto desempenho competitivo.

Ademais, dos 489 municípios analisados, 142 deles se encontram no intervalo de baixo nível de desempenho competitivo da agricultura familiar, sendo que as participações mais expressivas de municípios com essa classificação fazem parte da mesorregião Metropolitana de Porto Alegre e Sudoeste Rio-Grandense.

Tabela 8 - Distribuição das frequências absolutas e relativas do índice de desempenho competitivo da agricultura familiar (IDAF) nas mesorregiões gaúchas.

Mesorregiões Rio-

Grandenses
Índice de Desempenho Competitivo da Agricultura Familiar

\begin{tabular}{|c|c|c|c|c|c|}
\hline \multicolumn{2}{|c|}{ Baixo } & \multicolumn{2}{|c|}{ Intermediário } & \multicolumn{2}{|c|}{ Alto } \\
\hline fi & $\%$ & $\mathrm{fi}$ & $\%$ & fi & $\%$ \\
\hline 13 & 41,94 & 18 & 58,06 & - & - \\
\hline
\end{tabular}




\begin{tabular}{lcccccc} 
Centro Oriental & 6 & 11,11 & 48 & 88,89 & - & - \\
Metropolitana & 56 & 61,54 & 35 & 38,46 & - & - \\
Nordeste & 13 & 24,53 & 40 & 75,47 & - & - \\
Noroeste & 25 & 11,52 & 190 & 87,56 & 2 & 0,92 \\
Sudeste & 14 & 58,33 & 10 & 41,67 & - & - \\
Sudoeste & 15 & 78,95 & 4 & 21,05 & - & - \\
\hline Rio Grande do Sul & 142 & 29,04 & 345 & 70,55 & 2 & 0,41 \\
\hline
\end{tabular}

Fonte: Elaborado pelos autores com base nos dados da pesquisa.

Para complementar a análise sobre o desempenho competitivo da agricultura familiar nas mesorregiões gaúchas, a Tabela 9 destaca as principais estatísticas descritivas do índice de desempenho competitivo (IDAF) para os 489 municípios gaúchos considerados neste estudo, distribuídos em sete mesorregiões. Conforme se verifica, a mesorregião Noroeste Rio-grandense foi a que apresentou maior IDAF médio e menor coeficiente de variação. Dos 217 municípios que fazem parte dessa mesorregião, 105 deles possuem IDAF acima da média dessa mesorregião, sendo que o município de Carazinho foi o que obteve o maior IDAF no estado do Rio Grande do Sul. Em contrapartida, o menor IDAF foi encontrado no município de Lavras do Sul, localizado na mesorregião Sudoeste Rio-grandense, podendo ser influenciado pelo fato desse município ter apresentado o menor escore fatorial concernente à gestão competitiva sustentável.

A partir dos dados contidos nesta Tabela também se percebe que a maior heterogeneidade do índice de desempenho competitivo da agricultura familiar foi detectada ao se realizar a análise agregada para o estado do Rio Grande do Sul, visto que apresentou o maior coeficiente de variação. Em termos de mesorregiões Riograndenses, nota-se que a mesorregião Centro Ocidental foi a que deteve a maior variabilidade do IDAF.

Tabela 9 - Estatísticas descritivas dos índices de desempenho competitivo da agricultura familiar (IDAF) nas mesorregiões gaúchas.

\begin{tabular}{lcccccc}
\hline $\begin{array}{c}\text { Mesorregiões Rio- } \\
\text { Grandenses }\end{array}$ & $\begin{array}{c}\text { Número de } \\
\text { municípios }\end{array}$ & Mínimo & Média & Máximo & $\begin{array}{c}\text { Desvio } \\
\text { padrão }\end{array}$ & $\mathrm{CV}^{*}(\%)$ \\
\hline Centro Ocidental & 31 & 0,18 & 0,37 & 0,54 & 0,11 & 20,06 \\
Centro Oriental & 54 & 0,22 & 0,44 & 0,58 & 0,09 & 14,84 \\
Metropolitana & 91 & 0,21 & 0,35 & 0,63 & 0,08 & 13,37 \\
Nordeste & 53 & 0,22 & 0,42 & 0,70 & 0,10 & 14,10 \\
Noroeste & 217 & 0,21 & 0,46 & 0,71 & 0,09 & 12,80 \\
Sudeste & 24 & 0,16 & 0,35 & 0,55 & 0,11 & 19,02 \\
Sudoeste & 19 & 0,16 & 0,27 & 0,38 & 0,07 & 17,67 \\
\hline Rio Grande do Sul & 489 & 0,16 & 0,41 & 0,71 & 0,11 & 25,64 \\
\hline
\end{tabular}

Fonte: Elaborado pelos autores com base nos dados da pesquisa.

Nota: * Representa coeficiente de variação.

Com base nas Tabelas 8 e 9, observa-se que as mesorregiões Noroeste e Centro Oriental foram as que registraram melhor desempenho competitivo da agricultura familiar, visto que mais de $87 \%$ de seus municípios foram classificados como tendo 
nível de competitividade intermediário da agricultura familiar e obtiveram as maiores médias do IDAF. Desta forma, buscou-se verificar se há diferenças significativas entre a mesorregião Noroeste Rio-grandense, que teve o melhor desempenho da agricultura familiar com as demais mesorregiões. Para isso, determinou-se o teste $t$ de comparação de médias, cujos resultados se encontram na Tabela 10. Esses resultados confirmam que o índice de desempenho competitivo da agricultura familiar na mesorregião Noroeste Rio-grandense é significativamente diferente do índice de desempenho competitivo da agricultura familiar nas demais mesorregiões, excetuando apenas a mesorregião Centro Oriental, que não se mostrou significativamente diferente da mesorregião Noroeste Rio-grandense, com 95\% de confiança.

Tabela 10 - Testes para comparação de médias e de variâncias do índice de desempenho competitivo da agricultura familiar (IDAF) nas mesorregiões gaúchas.

\begin{tabular}{lccccc}
\hline Mesorregião gaúcha & Mesorregião gaúcha & \multicolumn{2}{c}{$\begin{array}{c}\text { Teste T de comparação } \\
\text { de Médias }\end{array}$} & \multicolumn{2}{c}{ Teste de Levene } \\
\cline { 3 - 6 } & Centro Ocidental & 4,56 & 0,00 & 4,38 & 0,04 \\
\hline & Centro Oriental & 1,57 & 0,12 & 0,01 & 0,94 \\
Noroeste & Metropolitana & 10,59 & 0,00 & 0,48 & 0,49 \\
& Nordeste & 3,40 & 0,00 & 0,42 & 0,52 \\
& Sudeste & 5,56 & 0,00 & 1,54 & 0,22 \\
& Sudoeste & 9,14 & 0,00 & 1,43 & 0,23 \\
\hline
\end{tabular}

Fonte: Elaborado pelos autores com base nos dados da pesquisa.

No tocante ao teste de Levene, os resultados indicam que todas as mesorregiões gaúchas apresentaram variâncias constantes do índice de desempenho competitivo da agricultura familiar, excetuando apenas a mesorregião Centro Ocidental, cujos municípios não possuem variâncias constantes do IDAF.

\section{CONSIDERAÇÕES FINAIS}

Os resultados permitiram verificar que a agricultura familiar nos municípios gaúchos apresenta nível de competitividade baixo e intermediário, tendo apenas dois municípios com elevado nível de competitividade. Isso corrobora aspectos como a baixa frequência de utilização de assistência técnica, reduzido uso de máquinas e equipamentos, assim como adoção de corretivos do solo pelos agricultores familiares. Dentre as mesorregiões Rio-grandenses, tais características estão presentes em maior número em estabelecimentos rurais no Sudoeste, na mesorregião Metropolitana de Porto Alegre e no Sudeste. Em contrapartida, o Noroeste e o Centro Oriental Rio-grandense foram as mesorregiões que apresentaram os melhores níveis de competitividade da agricultura familiar do Estado. 
Ademais, os resultados permitem concluir que há grande heterogeneidade nos municípios gaúchos quando analisado o nível de desempenho competitivo dos estabelecimentos rurais, fato que ressalta a necessidade de alternativas para o processo de modernização e crescimento da agricultura familiar. Essa evidência abre campo para novos estudos, tanto no que tange à análise dos aspectos técnicos, tecnológicos, como também dos comerciais e econômicos.

\section{REFERÊNCIAS}

BARBOSA, W. F; SOUSA, E. P. Desempenho competitivo dos apicultores fixos e migratórios da microrregião do Cariri, Ceará. Revista de Economia e Administração. São Paulo, v.11, n.1, p.5-27, 2012.

BRIXIUS, L.; AGUIAR, R.; MORAES, V. A. A força da agricultura familiar no Rio Grande do Sul. Extensão Rural e Desenvolvimento Sustentável. Porto Alegre, v.2, n.1/3, p. 7-15, 2006.

CORONEL, D. A.; AMORIM, A. L.; SOUSA, E. P.; BENDER FILHO, R. Limites e desafios da agricultura familiar, p. 250-258. In: LANA, R. P.; GUIMARÃES, G.; LIMA, G. S. Mutifuncionalidades sustentáveis no campo: agricultura, pecuária e florestas. Viçosa, MG, 2013.

ESSER, K.; HILLEBRAND, W.; MESSNER, D.; MEYER-STAMER, J. Competitividad sistémica: nuevo desafio a las empresas y a la política. Revista de la CEPAL, n. 59, p. 39-52, 1996.

FÁVERO, L. P.; BELFIORE, P.; SILVA, F. L.; CHAN, B. L. Análise de dados: modelagem multivariada para tomada de decisões. Rio de Janeiro. Elsevier, 2009.

FERRAZ, J. C.; KUPFER, D.; HAGUENAUER, L. Made in Brazil: desafios competitivos para a indústria. Rio de Janeiro: Campus, 1995.

FRANÇA, C. G.; GROSSI, M. E. D.; MARQUES, V. P. M. A. O censo agropecuário 2006 e a agricultura familiar no Brasil. Brasília: MDA, 2009.

GAMA, Z. J. C.; SANTANA, A. C.; MENDES, F. A. T.; KHAN, A. S. Índice de desempenho competitivo das empresas de móveis da Região Metropolitana de Belém. Revista de Economia e Agronegócio. Viçosa, MG, v. 5, n. 1, p. 127-159, 2007.

GUILHOTO, J. J. M.; ICHIHARA, S. M.; SILVEIRA, F. G.; DINIZ, B. P. C.; AZZONI, C. R.; MOREIRA, G. R. C. A importância da agricultura familiar no Brasil e em seus 
estados. In: Encontro Nacional de Economia, 36, 2007. Anais... Recife, PE: ANPEC, 2007.

IBGE - INSTITUTO BRASILEIRO DE GEOGRAFIA E ESTATÍSTICA. Censo Agropecuário 2006. Disponível em: <http://www.sidra.ibge.gov.br>. Acesso em: 16 mar. 2014.

MAIA, G. S.; KHAN, A. S.; SOUSA, E. P. Avaliação do impacto do Programa de Reforma Agrária Federal no Ceará: um estudo de caso. Economia Aplicada. Ribeirão Preto, v. 17, n. 3, p. 379-398, 2013.

PORTER, M. E. A vantagem competitiva das nações. Rio de Janeiro: Campus, 1993.

SANTANA, A. C. Análise da competitividade sistêmica da indústria de madeira no estado do Pará. Revista de Economia e Agronegócio. Viçosa, MG, v. 1, n. 2, p. 205$230,2003$.

Índice de desempenho competitivo das empresas de polpa de frutas do Estado do Pará. Revista de Economia e Sociologia Rural. Rio de Janeiro, v.45, n.3, p.749-775, 2007.

SOUSA, E. P.; CAMPOS, A. C. Desempenho competitivo dos fruticultores cearenses em diferentes áreas irrigadas. Revista Econômica do Nordeste. Fortaleza, v.41, n.1, p.155-166, 2010.

SOUSA, E. P.; SOARES, N. S.; SILVA, M. L. Desempenho competitivo das empresas de móveis de madeira: o caso do pólo moveleiro de Ubá - MG. Revista de Economia e Agronegócio. Viçosa, MG, v. 8, n. 3, p. 371-395, 2010.

TRIOLA, M F. Introdução à Estatística. 7 ed. Rio de Janeiro: LTC, 1999. 